\title{
Drug-Drug Interaction between Non-Steroidal Anti-Inflammatory and Angiotensin Receptor Blocker
}

\author{
Mahreen Muzammil ${ }^{1}$, Syed Saad Hussain ${ }^{* 2}$ \\ ${ }^{1}$ Department of Pharmacy Services, Aga Khan University Hospital, Karachi, Pakistan. \\ ${ }^{2}$ Pharmacy Department, Iqra University, Karachi, Pakistan.
}

\begin{abstract}
In pharmacotherapy, factors such as mode of administration, dose, and contraindications play a significant part in determining the optimal pharmacotherapeutic strategy. A drug's ability to influence the safety or efficacy of another drug (drug-drug interaction) is another factor to consider when choosing the best pharmacotherapy [1]. When multiple medications are prescribed at the same time, they may interact [2]. Drug-drug interactions (DDIs) can have a variety of outcomes, and adverse DDIs might result in patient death or drug withdrawal. Drug interactions can alter the pharmacokinetics and/or pharmacodynamics of a drug which may leads to therapeutic failure or any adverse drug event. Co-administration of naproxen with losartan will decrease the action of losartan which is an anti-hypertensive agent leads to uncontrolled hypertension. NSAIDs inhibit prostaglandin thus antagonise effect of converting enzyme inhibitors. Losartan is angiotensin receptor blocker, whose natriuretic effects decreased by naproxen.
\end{abstract}

Keywords: Drug-drug interaction, Pharmacotherapy, Tertiary care hospital, Naproxen, Losartan, Clinical pharmacy.

\section{BACKGROUND}

The important interaction highlighted as this case explained that the use of most commonly used medications especially NSAIDs in hypertension with angiotensin receptor blocker resulted in uncontrolled blood pressure. Naproxen (NSAIDs) antagonise the effects of losartan (ARBs).

\section{CASE PRESENTATION}

60-year-old female presented to ER with complain of head and neck pain. Upon examination hypertensive urgency was ruled out, she was managed on nitro-glycerine infusion for hypertension. After initial management patient admitted under internal medicine, pain killer prescribed to her to manage her pain for which she got admitted, was naproxen $500 \mathrm{mg}$ bid. It was discussed during round next day that even after 3 doses of amlodipine $5 \mathrm{mg}$ and 2 doses of losartan $50 \mathrm{mg}$ within last 24 hours, patient still required a third anti-hypertensive i.e., bisoprolol.

\section{INVESTIGATIONS}

Following investigations, clinical pharmacists discovered that when naproxen (an NSAID) is prescribed with losartan (ARBs), a drug-drug interactions by pharmacodynamic antagonism occurs [3]. Losartan's antihypertensive impact is reduced as a result of this interaction. This interaction was considered by the medical team.

\section{TREATMENT}

To compensate the effect of the drug-drug interaction. The

*Address correspondence to this author at the Pharmacy Department, Iqra University, Karachi, Pakistan.

Email: saad.hussain96@outlook.com causative agent i.e., naproxen was discontinued. To manage the pain experienced by the patient, the combination of acetaminophen in a dose of $650 \mathrm{mg}$, \& Orphenadrine in a dose of $350 \mathrm{mg}$ was prescribed for the next 24 hours. The blood pressure of the patient was managed by prescribing an angiotensin receptor blocker (ARB) i.e., Losartan Once daily \& Calcium channel blocker i.e., Amlodipine $5 \mathrm{mg}$ twice daily.

\section{DISCUSSION}

According to NICE guideline 2019, the first step for treating hypertension involves the administration of an Angiotensin Receptor Blocker (ARB) or an Angiotensin Converting Enzyme Inhibitor (ACEIs). Both drugs should not be co-administered. Addition of a Calcium Channel Blocker (CCBs) is recommended if hypertension is not managed by a single agent. The third step involves replacement of CCBs with a thiazide-like diuretic if CCBs cause oedema. According to Harris et al, among the ARBs, losartan is associated with the most drug-drug interaction (22\%). With the exception of calcium channel blockers, almost all drugs to treat hypertension are susceptible to lose their efficacy when co-administered with NSAIDs [4]. Due to the fact, calcium channel blockers have become the drug of choice when indicated to be co-administered with analgesics and anti-inflammatory drugs [5].

The key mechanism of action of NSAIDs is the blockage of prostaglandin biosynthesis via inhibition of cyclooxygenase-1 (COX-1). Reversible binding of naproxen is elicited with cyclooxygenase-1(COX-1) \& Cyclooxygenase-2 (COX-1), showing five times more affinity towards COX-1 [6]. A variety of physiological and pathophysiological organ 
function are elicited by prostaglandins, which are naturally occurring fatty acids [7].

Prostaglandin and renin reverse each other's effect. Prostaglandin (E-1 \& E-2) are responsible for vasodilation, increase blood flow, inhibition of adrenergic neurotransmission \& promotes excretion of fluids and electrolytes [8]. On the other hand, Angiotensin-II is responsible for vasoconstriction, reduction of renal blood flow, stimulation of adrenergic neurotransmission, and restricts water and electrolytes excretion. NSAIDs inhibit prostaglandin thus antagonise effect of converting enzyme inhibitor. Losartan is angiotensin receptor blocker whose natriuretic effects decreased by naproxen [9]. Acetaminophen had less effect on prostaglandin and when prostaglandin less inhibited after discontinuation of naproxen losartan produced its effects.

\section{LEARNING POINTS}

- One of the most remarkable actions of prostaglandins A \& $\mathrm{E}$ are their capacity to dilate peripheral blood vessels and thereby to reduce arterial blood pressure. However, naproxen inhibits prostaglandin action resulting in increase of blood pressure.

- For pain relief in hypertensive patients, Acetaminophen appears to be the safest analgesic.

- Avoid naproxen with Angiotensin converting enzyme inhibitor ACEIs

- Clinical pharmacists have great role in identifying possible drug interactions for the best therapeutic outcomes.

\section{AUTHORS' CONTRIBUTION}

Mahreen Muzammil: Case observation, Data collection, Analysis of observation, Draft manuscript preparation.

Syed Saad Hussain: Analysis of observation, Draft manuscript preparation, Final manuscript approval.

\section{CONFLICT OF INTEREST}

Declared none.

\section{ACKNOWLEDGEMENTS}

Declared none.

\section{REFERENCES}

[1] Food and Drug Administeration. Draft guidance for industry on drug interaction studies-study design, data analysis, implications for dosing, and labeling recommendations. Federal Register 2012; Available at: https://www.federalregister.gov/documents/2012/02/21/2012-3958/draft-guidance -for-industry-on-drug-interaction-studies-study-design-data-analysis-implications-for

[2] Juurlink DN, Mamdani M, Kopp A, Laupacis A, Redelmeier DA. Drug-drug interactions among elderly patients hospitalized for drug toxicity. JAMA 2003; 289(13): 1652-8.

[3] Rivkin A, Yin H. Evaluation of the role of the critical care pharmacist in identifying and avoiding or minimizing significant drug-drug interactions in medical intensive care patients. J Crit Care 2011; 26(1): 104.e1-6.

[4] Anggard E, Larsson C, Weber P. Interactions between the renal prostaglandins and the renin--angiotensin system. Adv Prostaglandin Thromboxane Res 1975; 2: 587-94.

[5] Johnston CI. Angiotensin receptor antagonists: focus on losartan. Lancet 1995; 346(8987): 1403-7.

[6] Botting RM. Mechanism of action of acetaminophen: Is there a cyclooxygenase 3? Clin Infect Dis 2000; 31(Suppl 5): S202-S10.

[7] Smith MC, Dunn MJ. The role of prostaglandins in human hypertension. Am J Kidney Dis 1985; 5(4): A32-A9.

[8] Anderson RJ, Berl T, McDonald KM, Schrier RW. Prostaglandins: Effects on blood pressure, renal blood flow, sodium and water excretion. Kidney Int 1976; 10(3): 205-15.

[9] Zhang W, Chen Y, Liu F, Luo F, Tian G, Li X. Predicting potential drug-drug interactions by integrating chemical, biological, phenotypic and network data. BMC Bioinformatics 2017; 18(1): 1-2. 